original papers

V. O'KEANE, A. JEFFERS, E. MOLONEY AND S. BARRY

\title{
Irish Psychiatric Association survey of psychiatric services in Ireland
}

\author{
AIMS AND METHOD \\ The Irish Psychiatric Association \\ conducted a national survey of \\ psychiatric services in Ireland to \\ examine clinical resources in relation \\ to the relative affluence of catch- \\ ment areas. A consultant psychiatrist \\ from each catchment area was sent a \\ postal survey form (August 2002) \\ and the data received were cross-
}

\author{
referenced with measures of relative \\ affluence. \\ RESULTS \\ There was a $72 \%$ response rate. A \\ negative relationship emerged \\ between indices of need and both \\ the number of acute beds and the \\ number of consultant psychiatrists \\ per head of the population.
}

\author{
CLINICAL IMPLICATIONS \\ The results of this survey indicate \\ that clinical resources in mental \\ health in Ireland are not \\ concentrated in areas of greatest \\ need, but paradoxically have been \\ best developed in areas of greatest \\ affluence.
}

The budget and planning for adult mental health services in the Republic of Ireland is devolved to local health boards, of which there are 10, servicing a total population of 3.9 million (Central Statistics Office, 2002). Although there are governmental Department of Health and Children guidelines for the development of psychiatric services, these date from 1984, and there is no central body coordinating this process. Scotland, which is comparable with Ireland demographically, has both a local and a central administrative system. A locally determined administrative structure is potentially sensitive to the needs of the local population, but may result in services not necessarily being concentrated in areas that have greater needs. In addition, the absence of a centralised planning body could potentially hinder the development of specialist services, many of which need to be evolved nationally because of the small population of Ireland.

An understanding of relative deprivation regionally is also important in terms of allocation of central resources, because areas of social deprivation have the highest rates of psychiatric disorders and the greatest need for services (Thornicroft, 1991; Jarman \& Sajekal, 1996). In contrast to the British National Health Service (NHS), where resources are theoretically allocated using an index that assumes that a greater proportion of the total resources for health care should be spent on mental health in more deprived areas (the York resource allocation formula: see Glover, 1999), there is no poverty-adjusted resource allocation system in Ireland. This is in spite of clearly identifiable areas of relative poverty among different health board populations: for example, levels of deprivation in the South Western Area Health Board population of $42 \%$ contrast with levels in the East Coast Area Health board population of $4 \%$ (both boards are located in the Dublin area) (Keogh et al, 1999). The same pattern is apparent outside the Dublin area, where levels of $30 \%$ in the South Eastern Health Board region contrast with levels of $4 \%$ in the Midland Health Board region (Walsh, 2002).

The other major determinant of need for public psychiatric services is the relative proportion of the population in any health board region using the public health care system. Approximately $30 \%$ of the Irish population have private health care insurance and 33\% have free health care (Medical Card holders). The vast majority of individuals with private medical insurance requiring psychiatric care receive this within the private psychiatric sector. The percentage of Medical Card holders in any district will thus to a large extent determine the demand for the service, and can vary widely from area to area: for example, $17 \%$ in south Dublin $v$. $51 \%$ in Donegal (north-west Ireland).

In order to examine the distribution of mental health resources among different regions of Ireland, the Irish Psychiatric Association (IPA) decided to conduct a survey. The objective of the survey was to provide a global, cross-sectional view of public psychiatric services in Ireland in 2002, in relation to the relative affluence of each area, and the demands for services.

\section{Method}

The Eastern Regional Health Authority (greater Dublin area) comprises three area health boards, and there are seven further health boards nationally. Each health board is further divided, for the purposes of delivering psychiatric care, into between two and five geographically defined catchment areas. There are a total of 32 psychiatric catchment areas, each of which is further subdivided into individual sector areas served by a consultant-led community mental health team.

\section{Measures}

A consultant psychiatrist (an IPA member) in each catchment area was sent a postal survey form, requesting demographic and clinical service information (survey forms are available from the authors upon request). The forms were sent in July and August 2002, with a request to return the completed form within 2 months. The data from each returned form were cross-referenced with data from a detailed survey of psychiatric services in the Dublin area (Keogh et al, 1999) and from the Report of 
the Inspector of Mental Hospitals for 2001 (Walsh, 2002). The latter is one of a series of reports published annually since 1987 by the Irish government, and documents the procedures, practices, clinical resources and service plans for each psychiatric service in the country. The report also provides basic demographic information and the budget allocation for each catchment area service.

To assess the relative affluence of each area, the Small Area Health Research Unit (SAHRU) index was used (Sinclair \& Kelly, 1999). This index has been compiled by the Department of Community Health and General Practice in Trinity College, Dublin and is based geographically on district electoral divisions. It rates indices of relative poverty on a scale of 1 to 5 , where 1 is the most affluent and 5 the most deprived. Deprivation is rated in terms specific to the particular socio-demographic conditions in Ireland. Finally, the percentage of Medical Card holders in each area gave an indication of the relative need for services. This information was sourced from the General Medical Services (Payment) Board of the Department of Health and Children.

\section{Analysis and statistics}

For each catchment area, individual services were examined in relation to the population size in order to standardise the data for comparative analysis. The computerised Statistical Package for the Social Sciences (version 11) was used for data analysis. Both parametric and non-parametric statistical tests were used where appropriate. Simple and multiple regression analyses were employed, with socio-demographic data as the independent variables and clinical resources as the dependent variables. Chisquared analysis was used for categorical analysis, and significance was set at $P<0.05$.

\section{Results}

A total of 23 consultants returned the survey forms, representing a $72 \%$ response rate. For the nine catchment area services for which no form was returned, a more limited analysis of the service was conducted, using information available from government publications. This latter analysis examined basic demographic information in relation to some readily available information on clinical resources, such as number of acute beds per head of population, but no information was available on specialist services for these areas.

In general terms, there were marked differences between catchment area services in most measures (Table 1). Sector populations varied from 16447 to 42 929. Numbers of psychologists in each catchment area service varied from 0 to 4 . There was a similar variation in psychiatric social worker and occupational therapy services. Acute bed provision, community residence availability and day facility provision demonstrated a similar wide variance.

\section{Acute bed numbers}

Clinical data were correlated with the number of Medical Card holders in each area. This revealed that the number of acute beds per 100000 of the population for catchment areas in Ireland $(n=32)$ were negatively, rather than positively, correlated with the number of Medical Card holders for each area $(\rho=-0.39, P=0.01)$. This association was significant for both the Eastern Region Health Authority $(=-0.75, n=10, P=0.007)$ and the rest of the country $(r=-0.36, n=22, P=0.05)$.

\section{Medical staffing}

A similar inverse relationship was found between the number of Medical Card holders and the number of consultant psychiatrists per 100000 population for all catchment areas surveyed ( $\rho=-0.39, n=23, P=0.03$ ). This national trend appeared to be accounted for by marked significance within the Dublin region $(r=-0.6$, $n=10, P=0.02$ ). Catchment areas in the rest of the country demonstrated a similar trend but this did not reach significance $(r=-0.35, P=0.12$ ). There was also a statistical correlation between the ratio of temporary to permanent consultant appointments and deprivation indices (percentage of district electoral divisions with a SAHRU rating of $4-5: r=0.35, n=23, P=0.048$ ).

Seventeen (55\%) clinical directors held temporary positions. When areas were divided according to whether

Table 1. Demographic statistics and clinical resources of the 32 Irish psychiatric service catchment areas

\begin{tabular}{|c|c|c|c|c|}
\hline & No. of areas & Median & 25th percentile & 75th percentile \\
\hline Catchment area size, $n$ & 23 & 26071 & 23501 & 34500 \\
\hline Medical Card holders per acute beds, $n$ & 32 & 12236 & 6946 & 17174 \\
\hline SAHRU level 4-5, \% population & 32 & 19.6 & 5.7 & 30 \\
\hline Acute beds per 10000 population, $n$ & 32 & 3.3 & 2.3 & 4.4 \\
\hline Community residential places per 10000 population, $n$ & 32 & 11.1 & 9.5 & 21.5 \\
\hline Medical Card holders per psychologist, $n$ & 23 & 15296 & 10322 & 24746 \\
\hline Medical Card holders per psychiatric social worker, $n$ & 23 & 11331 & 9856 & 16062 \\
\hline Medical Card holders per occupational therapist, $n$ & 23 & 10611 & 5734 & 16951 \\
\hline
\end{tabular}

SAHRU, Small Area Health Research Unit (level $4-5$ indicates relative poverty). 
7

original papers a quarter or more of the population held a Medical Card, 16 out of 17 areas with temporary clinical directors had populations where a quarter or more were Medical Card holders. When analysed categorically using $\chi^{2}$ testing, this was highly significant $(P=0.004)$.

\section{Non-medical staffing}

Psychology services were not available for $23 \%$ of catchment areas surveyed, and a similar pattern of erratic clinical resourcing emerged when this was cross-tabulated with need indices. Although not reaching statistical significance, there was a strong trend for the ratio of psychologists to be inversely related to the percentage of Medical Card holders in the catchment area $(r=0.36$, $n=23, P=0.09$ ). Similar trends were seen in occupational therapy provision across catchment areas, with the negative association between the ratios of occupational therapists to Medical Card holders almost reaching significance ( $r=-0.31, n=23, P=0.07$ ). The inverse ratio of occupational therapists to SAHRU deprivation scores for the Dublin region catchment area services almost reached statistical significance $(r=-0.5, n=10, P=0.06)$. There was no relationship between indices of need and the provision of psychiatric social workers.

\section{Specialist services}

The vast majority of services surveyed had no ready access to a range of specialist services: $94 \%$ had no access to neuropsychiatry; $88 \%$ had no services for eating disorders; $88 \%$ no adolescent psychiatry and 59\% no forensic service psychiatry (Table 2). The main determinant of access to a specialist service appeared to be geographical proximity to places where these services were provided.

\section{Discussion}

The fact that the information for this analysis was mostly drawn from postal questionnaires requires some comment. All the demographic information received was cross-referenced with official government publications (see Method). Where discrepancies existed, the Inspector of Mental Hospitals was contacted for clarification. In relation to information that could not be confirmed, such as non-medical staffing and specialist services, information was taken at face value. For the nine catchment areas $(28 \%)$ for which there was no completed questionnaire, demographic information was sourced from government publications. The non-participating areas were geographically and demographically disparate, and as a unit would have been unlikely to influence the outcome for the more clinical data, such as non-medical staffing. Completeness rate for the returned questionnaires returned was high (87\%), and most of the unanswered questions related to detailed demographic questions such as the percentage of Medical Card holders in the area.
Table 2. Specialist service availability in Ireland

\begin{tabular}{lc} 
Specialist service & Availability (\%) \\
\hline Rehabilitation & 65 \\
Old age & 53 \\
Liaison & 59 \\
Forensic & 41 \\
Perinatal & 6 \\
Child & 82 \\
Neuropsychiatry & 6 \\
Adolescent & 12 \\
Eating disorders & 12 \\
\hline
\end{tabular}

The findings of the survey were that rather than clinical resources following need, the reverse was true. There was an inverse relationship between acute bed availability and need, assessed using the relative number of Medical Card holders. Consistent with the finding of less well-developed services in deprived areas, this survey also found that the number of consultant psychiatrists, relative to population levels, was significantly lower in areas with the highest levels of social deprivation. More specifically, the number of temporary, rather than permanent, consultant psychiatrist appointments was greater in deprived areas. The relative number of temporary appointments is important because the position of temporary consultant psychiatrists employed long-term may be undermined by their temporary status, reducing their power to advocate necessary service developments. A startling $55 \%$ of the mental health services surveyed had non-permanent clinical directors - many of these in post for long numbers of years.

These findings are disquieting, and indicate that service development in Ireland has progressed without sufficient reference to socio-political or demographic realities. The association between socio-economic deprivation and increased need for psychiatric services underlies the formula for the allocation of resources in the UK, although in reality this may not always guide policy regionally (Bindman et al, 2000). The finding that the reverse process is occurring throughout Ireland, i.e. resources for mental health services appear to follow affluence, indicates that the current allocation system is further disadvantaging an already deprived group. The most obvious reason for this anomaly is that clinical resource allocation is being determined solely by local politics. Clinical resources also appear to follow effective clinical leadership, as demonstrated by the association between poorer clinical resource allocation and temporary consultant appointments, both at community mental health team and clinical director levels. The other potential cause for the mismatch between need and resources is the absence of a centralised policy that could oversee relative clinical resource allocation.

Basic specialist services (other than child psychiatry and psychiatry of old age) were generally not available outside Dublin, and availability within Dublin appeared to be contingent upon geographical proximity to specialist services. Dedicated adolescent psychiatric services were not available to $88 \%$ of the population. There was no 
specialist neuropsychiatric service available for the vast majority of the total population. Availability of eating disorder services was largely restricted to those domiciled in the Dublin area.

In summary, the results of this survey indicate that for many key services within mental health, clinical resources tend to be concentrated in the least deprived areas rather than the most deprived ones. The most deprived areas, defined by either SAHRU index or Medical Card status, have significantly fewer acute beds, larger sector sizes, and a greater ratio of temporary to permanent consultant psychiatrist staff. There are almost significant trends for the less deprived areas to have better access to psychology and occupational therapy services. Basic specialist services were not readily accessible in most of the catchment areas surveyed. Lastly, services in areas with higher proportions of Medical Card holders were significantly more likely to have temporary clinical directors in post.

\section{Acknowledgements}

The authors acknowledge the help received from Irish Psychiatric Association members, in particular Dr Dermot Walsh and Dr Michael Mulcahy, and the secretarial assistance of Ms Patricia Moran.

\section{References}

BINDMAN, J., GLOVER, G., GOLDBERG, D. et al (2000) Expenditure on mental health care by English health authorities: a potential cause of inequity. British Journal of Psychiatry, 177, 267-274

CENTRAL STATISTICS OFFICE (2002) 2002 Census. 183/2002. Dublin: Stationery Office (Government of Ireland).

GLOVER, G. R., ROBIN, E., EMAMI, J., et al (1999) A needs index for mental health care. Social Psychiatry and Psychiatric Epidemiology, 33, 89-96.

JARMAN, B. \& BAJEKAL, M. (1996)

Commentary on: An index of need for psychiatric services based on in-patient utilisation. British Journal of Psychiatry, 169, 317-321.

KEOGH, F., ROCHE, A. \& WALSH, D. (1999) 'We Have No Beds.. .'An Enquiry

*V. O'Keane Section of Perinatal Psychiatry, Institute of Psychiatry, De Crespigny Park, London SE5 9RS, UK (Tel: 0207848 0212; fax: 0207708 5919; e-mail:v.o'keane@iop.kcl.ac.uk), A. Jeffers East Galway Mental Health Services, Ballinasloe, Co. Roscommon, E. Moloney Cork University Hospital, Wilton, Co. Cork， S. Barry Cluain Mhuire Service, Newtownpark Road, Blackrock, Co. Dublin, Ireland
Availability and Use of Acute Psychiatric Beds in the Eastern Health Board Region. Dublin: Health Research Board.

CLAIR, H. \& KELLY, A. (1999) Deprivation indices: the need to keep socio-economic indicators separate. (rish Journal of Medical Science, 168(suppl. 10), 82

THORNICROFT, G. (1991) Social deprivation and rates of treated menta disorder. Developing statistical models to predict psychiatric service utilisation British Journal of Psychiatry, 158

WALSH, D. (2002) Report of the Inspector of Mental Hospitals for the year ending 31 December 2001. Dublin: Stationery Office (Government of Ireland). 